\title{
International online collaboration as a boundary crossing activity for vocational educators
}

\author{
Sarah Cornelius and Blair Stevenson
}

School of Education, University of Aberdeen, Aberdeen, AB24 5UA

Department of Media and Performing Arts, Oulu University of Applied Sciences, Oulu, Finland

s.cornelius@abdn.ac.uk, +44(0)1224 274616, @ sarahcornelius

blair.stevenson@oamk.fi, +358 401415285

Sarah Cornelius is a Senior Lecturer with expertise in post-compulsory education and digital learning. Her research explores teachers' and learners' experiences of technology enhanced learning in schools, vocational and Higher education. She has particular interests in online collaboration and mobile learning.

Dr Blair Stevenson is a Senior Lecturer at the Oulu University of Applied Sciences with research and professional background at the interfaces of teacher education, culture and technology. His research is interdisciplinary in nature and focuses on a range of topics including self-regulated learning, interdisciplinary methodologies and global education. 
International online collaboration as a boundary crossing activity for vocational educators

Vocational educators cross boundaries between practices in schools, colleges and workplaces, renegotiating their identities as professionals in a particular vocation and as educators. In order to support learners to enter the global workforce, they also require opportunities to cross boundaries through international practices. However, opportunities for international and intercultural learning are often limited, particularly for trainee vocational educators. This paper highlights an online collaborative process (COLIGE) designed to develop competencies for global education. The COLIGE process has been evaluated through the lens of boundary crossing. Participants were trainee vocational educators undergoing their professional teaching qualification in Scotland and Finland. Action research was undertaken during this three year project to explore participants' experiences and evaluate the learning mechanisms (Bakker and Akkerman 2017) observed during the activities. Findings suggest activity though all four learning mechanisms (identification, coordination, reflection, transformation), although they were not universally experienced. Difficulties faced by learners are discussed and point to the potential for transformation of practice without sequential engagement with all learning mechanisms.

Keywords: vocational teacher education, online collaboration, boundary crossing

\section{Introduction}

Vocational education is an internationally used term for professional-orientated training at the upper secondary and higher education levels. In many countries, vocational educators can gain a formal teacher qualification specifically for this context. In Scotland and Finland, vocational teacher education programmes are delivered by universities with oversight by formal accrediting agencies. Individuals undertaking vocational teaching qualifications have diverse academic and professional backgrounds, but are all expected to develop pedagogical and subject knowledge, skills to support successful learning and an understanding of the wider context in which they (will) 
work. In this way, they act in an interdisciplinary way across contexts, and require competencies such as the ability to appreciate different perspectives, knowledge of different disciplines, and resilience in the face of complexity (Spelt et al. 2009). They are also expected to cross academic and professional boundaries, including those between 'the community of the prior occupation's practice, the teaching occupation and the community of teacher training' (Fejes and Köpsén 2014, 265).

Fejes and Köpsén (2014) highlight the importance of balancing teacher and professional identities for vocational educators, and the role of boundary crossing in identity formation. Current issues of internationalisation and mobility suggest that an additional identity, that of 'global educator', is also necessary to prepare learners for the global workplace. However, whilst many vocational educators have strong local professional connections, opportunities to network and learn about wider international settings can be limited. Efforts have been made to support vocational educator movement across Europe (for example through ERASMUS+ $\operatorname{programmes}^{1}$ ), yet these are limited in scope. Further efforts are necessary to support trainee vocational teachers to gain competencies associated with working in international contexts. One way to support appropriate international interaction is through online education experiences.

Underpinned by growing recognition of the value of collaborative and positive interdependence between learners (Sharples, de Roock, Ferguson, Gaved, Heredotou, Koh, Kukulska-Hulme, Looi, McAndrew, Rienties, Weller and Wong 2016), online education experiences have rapidly expanded. They are facilitated by the use of digital

\footnotetext{
${ }^{1}$ See https://erasmusplus.org.uk/vocational-education-and-training-funding. This programme provides support for staff mobility and partnerships between European VET institutions.
} 
media and mobile technologies across higher education in Europe and globally (Mayer 2001). These experiences include, amongst others, interaction in Massive Open Online Courses (MOOCs), wiki supported co-creation of resources and communication between teachers and students through social media (Lee and Markey 2014; Lazar 2014; Cochrane, Bateman, Buchem, Camacho, Gordon, Keegan and Rhodes 2011). Examples of successful online collaboration within teacher education and across countries are increasingly being seen in the literature, however, these tend to be at the elementary and secondary levels (Dooly and Sadler 2013). Cases from vocational teacher education are rare. One example is a MOOC focused on the principles of social learning which reached 25,000 vocational educators from over 70 countries (Morris and Laurillard 2016). Another is the EDIT international video hackathon (Stevenson, Länsitie, Kogler and Bauer 2015) supporting the co-creation of educational videos within vocational teacher education across various European settings. Both of these examples promote collaboration between vocational educators across cultural and professional boundaries, and support interaction between different international settings. However, further work is necessary to fully integrate this type of boundary crossing within vocational teacher education programmes.

This paper outlines an online collaborative project designed to support the development of international perspectives amongst vocational teacher trainees. This project, COLIGE (Collaborative Online Learning In Global Education), was established in 2013 to bring together students on vocational teacher education programmes in Scotland (the Teaching Qualification Further Education (TQFE) at the University of Aberdeen) and Finland (iVet at Oulu University of Applied Sciences). A collaborative process was designed by the authors to allow trainee vocational educators to act across professional 
and pedagogic practices. This was ultimately assessed through the concept of boundary crossing, as this is well aligned with our view of competence development in the vocational sector. During the collaborative process boundary crossing was brokered by tutors (including the authors) and objects. Participants were encouraged to negotiate differences and combine expertise to inform practical action. Along with designing and implementing the process, the authors initiated a parallel action research project to assess learners' experiences and explore the underlying learning mechanisms (Bakker and Akkerman, 2017). This paper will summarise the project and focus on an analysis of the findings with an emphasis on the forms of boundary crossing undertaken. The remainder of the text is structured into six parts: theoretical background with an introduction to the concepts of boundary crossing and learning mechanisms, description of the COLIGE project, research methodology, findings, discussion and conclusions.

\section{Theoretical background}

This section outlines the key concepts grounding this paper - boundary crossing and learning mechanisms. Akkerman and Bakker (2011) explain boundaries as sociocultural differences that give rise to discontinuities in action or interaction. Boundaries of practice are places where misunderstandings and confusion can arise due to different regimes of competence (Wenger-Trayner, Fenton-O'Creevy, Hutchinson, Kubiak and Wenger-Trayner 2015). For a vocational educator these boundaries can arise between practices within their vocation and the practices associated with teaching. Boundary crossing is 'negotiating and combining ingredients from different contexts to achieve hybrid situations' (Engeström, Engeström, and Kärkkäinen 1995, 319). The vocational educator plays a role in connecting different cultures and practices to support their 
learners (Fejes and Köpsén, 2014). Crossing boundaries also contributes to identity formation, and Fejes and Köpsén (2014) suggest that teachers who can manage their identities effectively are the best prepared to teach.

Vocational educators continually cross boundaries between their own vocational area (e.g. construction, hairdressing, computer science, creative arts) and the educational context in which they work, where there may be different traditions, systems and terminologies. Trainee vocational educators have additional boundaries to cross between the academic context of the University and their practice setting. Adding an international element introduces yet more boundaries, and reveals socio-cultural differences. These differences include: the philosophical and political backgrounds of different vocational systems, the processes and terminology used in different countries, and those between different vocational teacher education programmes. Fejes and Köpsén (2014) suggest that vocational teachers have opportunities for multi-contexual learning through boundary crossing involving a range of different communities, including those related to their teacher education.

The potential of boundary crossing to support learning is acknowledged in theories such as expansive learning (Engeström 1987) and communities of practice (Wenger 1998)Additionally, Wenger-Trayner et al. (2015) suggest that crossing boundaries offers potential for learning by providing first hand experiences, generating new insights, and enhancing reflection on practice within communities. Others have also acknowledged the learning potential of boundary crossing to address complexity and support transformative, expansive learning (Engestrőm and Sannino 2010; Burch and Jackson 2012). Participation in different practices through boundary crossing provides opportunities for learning through encounters with both the familiar and the new (Fejes 
and Köpsén 2014). The process of reestablishing action or interaction across boundaries is also recognised as a fruitful space for learning (Akkerman and Bakker 2011).

Boundary crossing can be facilitated by both brokers (individuals acting as boundary crossers or boundary workers) who help to build bridges (Akkerman and Bakker 2011), and objects (activities or products acting as mediating artifacts which address multiple perspectives), which act as 'organic arrangements that allow different groups to work together' (Star 2010, cited in Akkerman and Bakker 2011, 140). Boundary crossing is often undertaken in a third space between different activity systems and requires participants to embrace change and challenge their own assumptions. In this way, the concept of boundary crossing connects with a parallel term 'third spaces' (Bhahba 2004; Stevenson 2015) which details the formation of practical and conceptual spaces 'in-between' that address epistemological and cultural differences.

Akkerman and Bakker (2011) provide a framework for learning through boundary crossing which covers four key mechanisms: (1) identification which supports coming to know about diverse practices in relation to one another; (2) coordination which suggests the creation of cooperative exchanges between practices; (3) reflection to expand perspectives on practices; and (4) transformation through collaboration and codevelopment of (new) practices. It is these four mechanisms that form the central focus of this paper. The next section outlines the design of the COLIGE project and identifies how it connects with the concept of learning mechanisms.

\section{Collaborative online learning in global education (COLIGE)}

The COLIGE project was designed to engage trainee vocational educators in an 
international experience and collaboration with international peers to: 1) enhance their understanding of the nature of learners in different contexts; and 2) develop competencies for global education. During the COLIGE process, trainees were brought together across their respective professional and educational practices, encouraged to negotiate differences and combine expertise to inform action. It was this effort to inform action which corresponded with the related action research component of the COLIGE project.

The COLIGE project was developed through an iterative process over three years, with feedback and evaluation continually informing activity (re)design. Throughout, teaching activity design was underpinned by a set of core principles intended to support accessibility and engagement (Stevenson and Cornelius, 2014). These principles stated that the process should:

- work within existing course structures and timetables and not become a significant additional activity;

- encourage collaborative activity and engagement with examples of authentic practice;

- use appropriate and accessible technology;

- build in opportunities for peer review and reflective dialogue; and

- accommodate diversity in participants' backgrounds, subject areas, confidence levels and technology skills.

Participants were encouraged to cross a range of boundaries, all of which offered opportunities for learning relevant to practice as a vocational educator. For the purposes of the project, boundaries were defined as: 
- $\quad$ socio-cultural (between cultures and societies);

- media and technological (between different media and technology as it relates to digital media literacy);

- $\quad$ vocational (between different disciplines); and

- $\quad$ pedagogical (between terminologies, policy and traditions).

Table 1 connects boundary crossings that were expected to take place during COLIGE with the specific learning mechanisms and the key tasks undertaken by students during the project. University tutors acted as brokers and boundary crossing was supported by specifically created objects including documents, emails and virtual spaces for interaction (such as a blog and virtual classroom). Shared understandings of educational theories and practice (for example lesson planning) provided a common starting point for interaction between the project participants.

[insert Table 1]

During the implementation of COLIGE project, key activities evolved through several iterations. However, in all cases activities centred on virtual interactions and joint completion of a lesson plan for teaching in the Scottish context. All of the tasks were designed to be integrated into the respective vocational teacher education programme in each country. This integration was facilitated by shared timetabling and consideration of respective assessment requirements (further details and templates associated with the activities of the project are available from slideshare.net/sarahcornelius). 
While this paper focuses on how the concept of boundary crossing connects to the COLIGE project, it is important to note that instructional design during the project's initiation was informed by another concept - computer-supported collaborative learning (CSCL). More specifically, Kirschner et al. (2004) outline key affordances and factors for supporting collaborative online educational interactions and learning which were considered as part of the COLIGE project initial design. These concepts were: task ownership (individual accountability and positive interdependence of collaborators); task character (the level of authenticity of a task and how motivating and stimulating it is); and task control (the degree to which collaborators can direct their own learning experiences). Specific actions were taken to address these ideas. In Year 1 a 'global education' theme informed lesson design, but task ownership and control was improved in later years by allowing learners to select a theme relevant to their own work and study requirements. Positive independence was supported through careful sequencing of tasks that required exchange of information and resources. Task control was facilitated by refining instructions and the establishment of a project blog, which proved particularly helpful for clarifying expectations. Phielix, Prins, Kirschner, Erkens and Jaspers (2011) suggest that participants in computer-supported collaborative learning environments may limit their actions to cognitive processes to the detriment of socioemotional processes, and the development and review of socialization activities within COLIGE attempted to address this issue. For example, in Year 1 participants were required to exchange emails and share photographs of their context. By Year 3 this approach had been revised and learners were encouraged to swap videos and engage in live online discussions to give richer insights into their context and practice.

In addition to the changes to the COLIGE process outlined above other developments resulted from reflection and feedback throughout the project. These included an 
increased emphasis on modeling and participation by tutors, development of a shared 'focal point' for the activity (the blog), building of social relationships between participants through the addition of online sessions, and enhanced use of multimedia to encourage group interaction.

The COLIGE process was implemented in three successive academic years with varying numbers of participants (see Table 2) from a range of colleges in Scotland and an English language vocational teacher training programme in Finland. In Scotland, participants were in-service trainees undertaking the Teaching Qualification in Further Education (TQFE), while in Finland participants were pre-service trainees on the vocational teacher education programme (iVET).

\section{Research approach and methodology}

A research process was initiated as part of the COLIGE project as an action research approach incorporating a self-reflective methodology (Carr and Kemmis, 1986) to allow participants to 'reflect systematically about the terms and conditions that shape their practice' (Elliot, 2007, p. 2). The specific research question explored was: how can participation in an online collaboration support boundary crossing for trainee vocational educators?

Ethical approval was obtained for mixed methods action research with data collection through student evaluation, reflective dialogue, key informant interviews and focus groups. At the end of each year of the project, COLIGE participants were invited to complete a questionnaire to provide general comments on activity effectiveness and their attitudes and experiences. Table 2 provides information on questionnaire response 
rates and respondent characteristics. Data from questionnaires were considered alongside tutors' reflective comments, which were captured through semi-structured dialogue and supported by course artefacts and tutors' notes. When opportunities arose (for example in year 2) discussions were held with key informants, including staff with professional development responsibilities in vocational institutions. These discussions covered existing approaches to providing international experiences, challenges and issues and the design of future activities. In year 3, a semi-structured focus group was conducted with Scottish COLIGE participants to explore their experiences of the process and consider the impact of global learning on practice. This particular focus group allowed for validation of other data sources.

[insert Table 2]

In line with an action research approach, analysis was conducted after each implementation of COLIGE, and combined with other feedback to inform the development of the approach. Questionnaire data provided demographic information and descriptive statistics, whilst initial analysis of transcripts provided evidence of learners' experiences, successes and barriers. This paper pulls together findings at the end of the project to explore learning through the boundary crossing lens, formulate lessons learnt and validate across sources. To support this, transcripts of discussions and dialogues were analysed by both researchers independently to identify evidence for learning by using the four learning mechanisms identified by Akkerman and Bakker (2011) as a conceptual framework. Closed coding was formulated according to the four learning mechanisms. These categories were informed by the articulation of corresponding phrases to help identify evidence for the learning mechanisms within the COLIGE process. Examples of phrases corresponding to each mechanism included: 
- identification: 'participants are engaged in socialisation activities', 'getting to know each other' and 'exchanging information about their teaching contexts';

- coordination: 'development of a lesson plan drawing on discussions', and 'exchange of information about practice in both contexts';

- reflection: 'group dialogue and individual reflection on practice demonstrating recognition' and 'consideration of different perspectives', and 'querying of existing assumptions and beliefs'; and

- transformation: 'application of new ideas and knowledge emerging from international collaboration to local practice'.

Evidence was identified by researchers individually and then discussed together to come to a shared view of examples of boundary crossing. Alternative interpretations and cases where supporting evidence was limited or spread across several sources of data were also explored further.

\section{Findings}

Findings are presented in four sections below, each corresponding with one of the four learning mechanisms within the Akkerman and Bakker (2011) framework: identification, coordination, reflection and transformation. In each section, specific evidence of learning mechanisms in action is presented and discussed as drawn from project data. 


\section{Identification}

The mechanism of identification supports learning through the development of insights about how practices or roles are different across boundaries (Akkerman and Bakker, 2017). During the COLIGE process opportunities for learning through identification were afforded by crossing socio-cultural, technological, vocational, and pedagogical boundaries. Guided dialogue between participants and the exchange of information about vocational education contexts in Scotland and Finland allowed the exploration of similarities and differences and facilitated effective communication. In year 3, for example, tutor explanations of the process, video selfies and email introductions encouraged initial interaction and discussion of respective contexts, which participants then continued using media and technologies of their choice. Findings from surveys indicate that the opportunities to collaborate with peers in another country and to learn from another context were viewed as key positive aspects of the activity. The majority of participants made contact with activity partners and exchanged information about classes (see Figure 1). In year 3,100\% of survey respondents were able to make initial contact with their task partners. Participants across all years highlighted that they gained insight into how practices or roles in the two settings compared. For example, a Scottish student in year 1 noted that it was 'interesting to hear what other lecturers do and how it varies or is similar to our lecturers', and a peer in year 1 felt that one of the impacts of the activity was 'knowing that other people in another country experience similar teaching/learning scenarios to myself'. Reflecting on an online discussion another year 1 student commented that across the two countries 'barriers and challenges always seem to be the same'.

However, comments also suggest that making and maintaining contact with peers was a 
logistical challenge for some students and to some represented an insurmountable barrier to collaboration. For example, finding time to communicate was deemed as problematic by one focus group respondent who stated that she had 'opted out' after delays in making contact and confusion over partners. Sometimes differences in professional backgrounds or lack of common ground impacted on the development of relationships and insights gained - the vocational boundaries were perhaps too challenging to cross or seen as unnecessary obstacles in these cases. Other issues hampering the exchange of information were time, the commitment of individuals and a lack of understanding of the task. This finding is demonstrated well by a student in year 3 who commented that they 'had to accept that my partner was nowhere near as dedicated as I was' whilst another in year 1 highlighted time issues: 'unfortunately I was unable to participate because of work duties and I was unable to get time off'. For Scottish students, there was evidence that their engagement was influenced by the relationship between COLIGE and their local summative assignment task, and some felt that links between the COLIGE tasks and their local assessment requirements should have been made more explicit to facilitate the completion of the activities.

The measures taken and adapted throughout the COLIGE process to support the learning mechanism of identification - the development of insight into how practices or roles are different or complementary - appear to have been appropriate, but were located within a wider context of the development of personal and professional relationships with international peers. In order to support effective learning through boundary crossing in COLIGE, commitment from individuals and adequate time to participate was critical, and supporting boundary objects should provide clear information about processes and expectations, without constraining individuals. It also appears that if one 
boundary (for instance between vocational or technological practices) was perceived as insurmountable, then this had a negative impact on some participants' engagement in the collaborative process.

\section{Coordination}

Bakker and Akkerman (2011) suggest that coordination includes a range of processes to support continuity in action and future and effortless movement between sites. This learning mechanism suggests that cooperative exchanges can be created and sustained across boundaries with the help of boundary objects. The boundaries associated with this learning mechanism in COLIGE were primarily pedagogical and vocational, with participants focused on a key activity - the generation of a joint lesson plan. Media and technological boundaries also played a part, with negotiation necessary over the nature of their product and method of production. The most important boundary objects in the COLIGE activity were the overall lesson planning activity, and the template document designed to support completion of this action. The task of producing a lesson plan required commitment from both parties, with the Scottish student(s) first sharing details of a class, followed by discussion of the context involving both parties. This stage required discussion of pedagogical practices to explore different learning contexts, uncover differences in terminology and surface assumptions about others' expectations and practice. The Finnish student(s) then designed and shared a lesson plan on which the Scottish student(s) provided feedback. This lesson plan was an important product from which emerged insights about how practices were different or similar. An optional task for the Scottish student was to implement the lesson plan or for collaborating groups to engage in further joint reflection and evaluation. Figure 1 shows the progress made by students through the activity in years 2 and 3 . Note that 
only Scottish students were required to provide information about their class so the lower absolute levels for completion of this task are expected.

[insert Figure 1]

Working together on the tasks was noted by participants as a highlight of the activity. Key positive aspects of the activity included 'working with partner in [an]other country' (year 2 student), 'collaboration' (year 3 student) and 'active participation' (year 3 student). However, for other participants difficulties were experienced. A year 3 student felt that they learnt 'about the difficulty of collaborating'. Difficulties experienced in years 2 and 3 included not receiving replies from partners, a lack of detailed feedback, differing levels of commitment, lack of understanding of requirements and different expectations between students working together. The time available to collaborate was also an issue that had an impact on engagement. For example, the overall activity timeframe was considered too short by some respondents. However, the high level of contact reported in year 3 suggests that measures taken to generate interest in the task, by providing clear instructions and ensuring that students were willing to contribute to the activity had met with some success in later stages of the project.

Figure 1 shows a clear drop in engagement at two stages in year 3: 1) after making initial contact, and 2) when students were required to provide feedback on the lesson plan. Tutor reflections suggest that there was a similar pattern of engagement in year 1. Comments from survey respondents suggest that they valued peer feedback: for instance the 'possibility of receiving feedback from the implemented lesson' (year 2 student) and 
'looking forward to getting feedback from my partner' (year 3 student) were noted as positive aspects, yet feedback was not always forthcoming. Survey respondents noted that it was 'difficult to relate to a [different] subject area' (year 3 student), and that there could be 'missing common ground' (year 3 student) if pairs did not come from the same professional background. Despite efforts to match students in similar subject areas together for the activity, this was not always possible and vocational boundaries remained challenging for some. Groups were created to try to address this in year 3, but this was still a stage at which students dropped out of the activity. Assessment may also have a role to play since Finnish students were required to submit the lesson plan created for their specific studies, whereas the activity was optional for Scottish participants. Ultimately, if feedback was an optional step, then students may have elected to skip this.

Findings also suggest that the key mediating boundary object for this activity, the task instructions and template, provided support for coordination, but that there were many instances where the activity was not sustained and the opportunities for learning were missed. Maintaining effective communication across boundaries to support the development of a product was a particular challenge. It is possible that learning through this mechanism could have been enhanced with greater input from boundary workers (tutors), or development of measures to help participants overcome some of the barriers to their engagement.

\section{Reflection}


Tasks to encourage reflection were incorporated throughout the COLIGE activity and opportunities for reflective dialogue were built in, for instance during joint online webinars and at local workshop sessions. Akkerman and Bakker (2011) note the influence of generating a product in developing new perspectives, drawing on a Bakhtinian view that perspective making and taking are dialogical and creative. As a result, data were sought from participants to ascertain whether they had become more aware of their own perspectives or gained appreciation of alternative perspectives. It is noteworthy, however, that the data collected explores whether alternative perspectives were recognised by participants, but does not specify the factors that brought about these alternatives. Findings point to several students in year 1 commenting on the success or impact of the activity in terms of a change in perspective. These comments ranged from the general ('seeing things from a different point of view', and 'you consider avenues of learning that you have not previously applied') to specific impacts relevant to practice. Comments received included: 'it has provided me with a new perspective when teaching on a daily basis'; and 'I appreciated receiving a lesson plan from another lecturer and seeing their viewpoint on how something can be done differently'. In addition, one year 3 student commented on the value of engaging with another perspective to support preparation of an assignment. These comments suggest that where the COLIGE process was successful, all of the boundary crossings involved (socio-cultural, technological, pedagogical, and vocational) were successfully navigated, and new insights were supporting reflection on existing practice and on new possibilities for practice. Learning through new perspectives was possible through the activity with some participants prompted to look anew at practice. Further research is needed to more closely assess what led to changes in perspectives, for example which 
boundary crossings were particularly important, and how these could be encouraged further.

\section{Transformation}

Bakker and Akkerman (2017) propose that individuals can be transformed through boundary crossing. The final learning mechanism associated with boundary crossing - transformation - was observed through changes to existing practices or the development of new ones. These changes were defined in the project as the application of new ideas and knowledge to local practices as a result of the international collaboration.

At an individual level, learners reported increased coverage of international issues in their lessons, and that their own students were very interested to discuss these topics. For example, a year 1 participant commented: 'I will incorporate the ideas raised in the lesson plan as a trial this year and hope to develop thereafter'. There were also reports of the development of IT skills with support from the international peer, with the use of new software such as Padlet and Skype to facilitate communication and collaboration. In both of these cases, boundary crossing supported specific developments in practice. One focus group respondent stated:

'It did teach me how to use technology a bit more. Online collaboration is not something I'm used to in my practice, but I learnt some new techniques and how to use the technology' (year 3 focus group respondent).

Strong connections were also made between individual participants when professional similarities were found and hopes were expressed that collaboration could continue. The ways in which individuals were changing their practices is exemplified in the following 
quotation from one focus group respondent:

"It definitely helped me. I got quite far down the road. I implemented the lesson plan that was designed by my Finnish partner and videoed that lesson and as part of that we also discussed the room layout so I changed the room layout which I'd never done before, and I used tablets in the room in group work, again I'd never done that before" (year 3 focus group respondent).

At the wider institutional level, as a result of the COLIGE project new resources were introduced into the Scottish programme of study to enhance consideration and discussion of international issues and intercultural communication. Additionally, one of the Scottish colleges set up opportunities for Finnish students to visit them, and another organised a site visit to Finland to expand understanding of the Finnish vocational system. These activities will have an enduring impact on those involved and help to encourage others to engage with international collaboration. This form of boundary crossing is reflected well in a response from a year 3 participant:

'we are very glad we did it because we are here now [in Finland]! One of the enduring things is that there has been this follow through ... the physical collaboration of us coming here. We're not going to forget it' (year 3 focus group respondent).

As highlighted in participants' comments, there is clear evidence of transformation in the practice of individuals and institutions involved in the project. Specifically, it was observed that COLIGE helped to create opportunities for further learning and raised awareness of the value of international collaboration for vocational educators and institutions. One respondent summarised this well by stating that 'collaboration, especially with international peers, provides a large pool of knowledge which we can all share and extract ideas which would benefit our learner groups', while another year 1 webinar participant stated that '[it] would be a great activity for the college to engage 
with on a regular basis $[\ldots]$ and for our students to be able to chat like this'.

\section{Discussion}

Findings presented above suggest that the COLIGE process provided opportunities for boundary crossing and learning according to all four of the boundary crossing learning mechanisms outlined by Akkerman and Bakker (2011). However, there is also evidence that these opportunities were not universally experienced. Whilst identification might seem the easiest mechanism to support in an online context, this was not always the case, and barriers experienced at this stage impacted severely on some participants. Despite the iterative design of boundary objects and approaches to mediation, coordination amongst students was not always successful, and did not serve to erase or decrease boundaries in all cases. And yet, some evidence of reflection to support changes to perspectives exists in the findings among students who completed the whole process, along with examples of transformation amongst these students and at a wider institutional level.

Overall, boundary crossing and learning mechanisms provided a useful framework for exploring learning through COLIGE, since they support the argument that even when difficulties impacted on participation and progress through tasks, positive learning outcomes could be reached. The crossing of boundaries between international vocational education contexts has clear learning potential, particularly if the right conditions are created. These conditions warrant further investigation, but findings presented here suggest the following requirements: 
- the creation of opportunities for effective relationship building and communication across boundaries to support identification and provide a foundation for other learning mechanisms;

- development of shared understandings of the purpose of boundary crossing, tasks involved and individual responsibilities to support coordination; and

- facilitation of opportunities for individual reflection and collective dialogue to support reflection.

Bakker and Akkerman (2017) suggest that reflection might be conditional for transformation. However, some of the examples of transformational learning cited above, for example the development of new activities for a course and establishment of international exchanges, are difficult to link specifically to the reflection required during the activity. Thus, boundary crossing activities might have potentially wider learning potential with impacts on other stakeholders as well as those learners directly involved. In this instance, the brokers (tutors) acknowledge their own learning from the activity, and other interested parties (including local mentors and past course participants) have also benefitted.

A further outcome of boundary crossing is noted by participants who suggested that the activity supported their vocational teacher education goals. One participant in year 2 noted that the benefit of the activity was that it 'helped me get credits', while another in year 3 suggested that it had been 'beneficial to my [assessment] challenge'. Their focus on assessment is understandable in a context involving adult learners balancing the requirement for professional accreditation with other commitments and responsibilities. 
The need to consider carefully the status and role of an international collaborative activity is also acknowledged by Sadler and Dooly (2016) who after twelve years of experimentation with online collaboration on a US/Spain partnership involving primary teachers reported that their collaboration moved from 'being peripheral to becoming the central nexus for the learning process' (p. 7), As a result a common curriculum was created where there had previously been two. In the face of different national standards and frameworks, similar alignment within the COLIGE process may be difficult to achieve due to the national guidelines for vocational teacher education programmes in both Finland and Scotland. In our contexts, the standardisation of different curricula and assessment may not be achievable or even desirable.

\section{Implications for theory and practice}

Exploring the COLIGE activity through a boundary crossing lens, and more specifically using the four learning mechanisms proposed by Akkerman and Bakker (2011), has provided a useful framework for discussion and exploration of issues and challenges faced by learners. The learning mechanism framework complements other approaches to online learning design (e.g. Kirschner et al. 2004), and provides a tool to investigate where and how learning has taken place in the interface between differing contexts. Using the framework as an analytical tool has also proven useful for categorising feedback on learners' experiences, and led to further consideration of how the COLIGE process could be revised further to support effective learning. Measures to encourage communication at each stage, and modelling by tutors in their role as boundary brokers, need further consideration. Careful matching of participants across boundaries is needed to ensure that shared understandings are reached and a secure basis for collaboration established. The nature and role of boundary objects used to support coordination is also deemed to be critical. 
In our findings cases exist that suggest that learning within one mechanism is not necessarily dependent on following other mechanisms sequentially. Rather, findings point to more of a cyclical progression through the various mechanisms such that transformation can take place alongside coordination or identification, and reflection can be experienced at the same time. Furthermore, examples of transformation before reflection, and transformation for wider stakeholders, warrant further exploration. The idea of engaging in multiple learning mechanisms simultaneously may be related to the status of the project participants as trainee teachers, and apply to other professional learners who are encouraged to be reflective practitioners. The extension of learning beyond the personal experiences of the participants into transformations in their professional workplaces, as noted by various respondents, also points to the power of boundary crossing as a mechanism for professional learning, further illustrating the wider benefits of the framework.

\section{Conclusion}

This paper summarises a three-year international, online, collaborative project (COLIGE) designed as a learning opportunity for vocational educators undergoing their professional teaching qualifications in two countries (Scotland and Finland). Data collected from multiple sources were used to assess the learning potential of the activity and explore its effectiveness to support the learning of vocational teacher trainees. Analysis of data was conducted using a conceptual framework of learning mechanisms for boundary crossing (Akkerman and Bakker 2011). Through the lens of this framework, findings point to project participants being engaged in boundary crossing associated with their professional and teaching domains. Overall, it is suggested that boundary crossing and the concept of learning mechanisms provides a useful framework 
for exploring the online, international, collaborative learning, such as that which took place through the COLIGE process. Furthermore, collaborative boundary crossing between international vocational education contexts has clear learning potential, particularly if the design of tasks creates effective opportunities for relationship building, communication, shared understandings of purpose and opportunities for individual and collective reflection and dialogue.

The findings further suggest that boundary crossing can be both highly personal or collective, with outcomes only seen for individuals and others common across the wider community of learners. Participants' experiences also revealed instances of transformational learning which may not have been conditional upon a sequential progression through each learning mechanism. Even though this research focused on a project with a relatively small sample size, it points to the need for further research to explore what makes for effective design and implementation of collaborative online learning in vocational contexts, specifically to support effective small group working and reflection between participants in different locations and from different cultural contexts.

Acknowledgements

The authors acknowledge the support of many colleagues in their respective universities and within partner colleges during this research. Course tutors in Scotland, Dr Margaret Harris and Dr Aileen Ackland, are thanked for their support in implementing COLIGE with their students. Students who completed surveys or provided feedback in other ways are also thanked for their helpful comments. Professor Paul Kirschner kindly engaged in discussions associated with this work and colleagues and anonymous reviewers have provided helpful feedback on draft versions of this paper.

References 
Akkerman, S. F., and Bakker A. 2011. Boundary crossing and boundary objects. Review of Educational Research 81, no. 2: 132-169.

Bakker, A., and Akkerman, S. F. 2017. The learning potential of boundary crossing in the vocational curriculum. In Unwin, L. and Guile, D. Handbook on vocational education. Wiley. available from https://www.researchgate.net/publication/303952075_The_learning_potential_of _boundary_crossing_in_the_vocational_curriculum

Bhahba, H. 2004. The Location of Culture. London: Routledge.

Burch, J. and Jackson, A. 2012. Developing Partnership through third space activity. University of Cumbria: http://my.cumbria.ac.uk/Courses/SubjectAreas/Education/Research/TEAN/Teac herEducatorsStorehouse/Partnership/DevelopingPartnershipThroughThirdSpace

\section{Activity.aspx}

Carr, W. and Kemmis, S. 1986. Becoming Critical: Education, Knowledge, and Action Research. London: Falmer Press.

Cochrane, T., Bateman, R., Buchem, I., Camacho, M., Gordon, A., Keegan., H. and Rhodes, D. 2011. MLearning 2.0: fostering international collaboration. In Candel Torres, I. et al. (eds.) ICERI2011: $4^{\text {th }}$ International Conference of Education, Research and Innovations. Madrid, Spain: IATEC: 42-51.

Dooly, M., and Sadler, R. 2013. Filling in the gaps: linking theory and practice through telecollaboration in teacher education. ReCALL, 25, no. 1: 4-29.

Elliot, J. (2007). Reflecting Where the Action Is: Selected Works of John Elliot. Routledge: New York.

Engeström, Y. 1987. Learning by expanding. An activity-theoretical approach to developmental research. Helsinki, Finland: Orienta-Konsultit.

Engeström, Y., Engeström, R., and Kärkkäinen, M. 1995. Polycontextuality and boundary crossing in expert cognition: learning and problem solving in complex work activities. Learning and Instruction, 5 no. 4: 319-336.

Engestrom, Y. and Sannino, A. 2010. Studies of expansive learning: Foundation, findings and future challenges Educational Research Review, vol. 5, pp. 1-24.

Fejes, A., and S. Köpsén. 2014. Vocational teachers identity formation through boundary crossing. Journal of Education and Work, 27 no. 3: 265-283. 
Kirschner, P., Strijbos, J., Krekjns, K., and Beers, P. J. 2004. Designing electronic collaborative learning environments. Educational Technology Research and Development, 52 no. 3: 47-66.

Lazar, I. 2014. EFL learners' intercultural competence development in an international web collaboration project. The Language Learning Journal. DOI $10.1080 / 09571736.2013 .869941$

Lee, L. and Markey, A. 2014. A study of learners' perceptions of online intercultural exchange through web 2.0 technologies. ReCALL. DOI $10.1017 / \mathrm{S} 0958340014000111$

Mayer, R. 2001. Multi-media Learning. New York: Cambridge University Press. Morris, N., and Laurillard, D. 2016. Blended Learning Essentials MOOC. Alt-C Blog, April 2016. https://altc.alt.ac.uk/blog/2016/04/blended-learning-essentials-mooc/

Phielix, C., Prins, F. J., Kirschner, P. A., Erkens, G., and Jaspers, J. 2011. Group awareness of social and cognitive performance in a CSCL environment: Effects of a peer feedback and reflection tool. Computers in Human Behavior, 27 no. 3: 1087-1102. doi:10.1016/j.chb.2010.06.024

Sadler, R. and Dooly, M. 2016. Twelve years of telecollaboration: what we have learnt. ELT Journal Advance Access, June 2016 ELT Journal doi:10.1093/elt/ccw041 Salmon, G. 2011. e-Moderation: the key to teaching and learning online. $3^{\text {rd }}$ edition. New York: Routledge.

Sharples, M., de Roock, R., Ferguson, R., Gaved, M., Heredotou, C., Koh, E., Kukulska-Hulme, A., Looi, C.-K., McAndrew, P., Rienties, B., Weller, M., and Wong, L. H. 2016. Innovating Pedagogy 2016. Open University Innovation Report no. 5. UK: Open University http://proxima.iet.open.ac.uk/public/innovating_pedagogy_2016.pdf

Spelt, E. J. H., Biemans, H. J. A., Tobi, H., Luning, P. A. and Mulder, M. 2009. Teaching and learning in interdisciplinary higher education: a systematic review. Educational Psychology Review, 21 no. 365. doi:10.1007/s10648-009-9113-z

Star, S. L. 2010. This is not a boundary object: reflections on the origin of a concept. Science, Technology and Human Values, 35: 601-617

Stevenson, B., and Cornelius, S. 2014. Developing an online collaborative approach to global education in vocational contexts. Journal of Perspectives in Applied Academic Practice, 2 no. 1 http://jpaap.napier.ac.uk/index.php/JPAAP/article/view/99 
Stevenson, B., Lansitie, J., Kogler, C., and Bauer, P. 2015. Exploring co-creation of videos in an international collaborative context. Journal of e-Learning and Knowledge Society, 11 no. 2 http://je-lks.org/ojs/index.php/JeLKS_EN/article/view/1018/937

Stevenson, B. 2015. Third spaces and video-stimulated recall: an exploration of teachers' cultural role in an Indigenous education context. Educational Action Research, 23 no. 2: 290-305.

Wenger, E. 1998. Communities of practice, learning, meaning and identity. Cambridge. UK: Cambridge

Wenger-Trayner, E., Fenton-O'Creevey, M., Hutchinson, S., Kubiak, C., and WengerTrayner, B. 2015. Learning in Landscapes of Practice: boundaries, identity and knowledgeability in practice-based learning. Abingdon, UK: Routledge. 
Table 1: Expected boundary crossing and learning mechanisms (from Akkerman and Bakker 2011) in relation to the COLIGE process

\section{Expected boundary Expected COLIGE activity crossing

Socio-cultural, media Identification and technological, vocational, pedagogical

Vocational, Coordination pedagogical

Socio-cultural, media Reflection and technological, vocational, pedagogical
Task 1: Socialization and making initial contact participants get to know each other

Task 2: exchange of information about teaching contexts

Task 3: Development of a lesson plan for a Scottish class drawing on discussions and exchange of information about practice in the two international contexts

Tasks 4 and 5: Individual reflection, group dialogue and supported reflection on practice

Transformation Optional task: Delivery of lesson. Application of new ideas and knowledge to local practice 
Table 2: Questionnaire response rates and respondent characteristics

\begin{tabular}{|c|c|c|c|c|}
\hline & Year 1 & Year 2 & Year 3 & Total \\
\hline Number of students undertaking COLIGE & 17 & 16 & 30 & 63 \\
\hline Number of questionnaire responses & 8 & 6 & 11 & 25 \\
\hline Response rate & $47 \%$ & $37.5 \%$ & $36.7 \%$ & $39.7 \%$ \\
\hline Number of respondents studying in Finland & 3 & 4 & 4 & 11 \\
\hline Number of respondents studying in Scotland & 5 & 2 & 7 & 14 \\
\hline
\end{tabular}


Figure 1: Progress through the COLIGE activity tasks in years 2 and 3

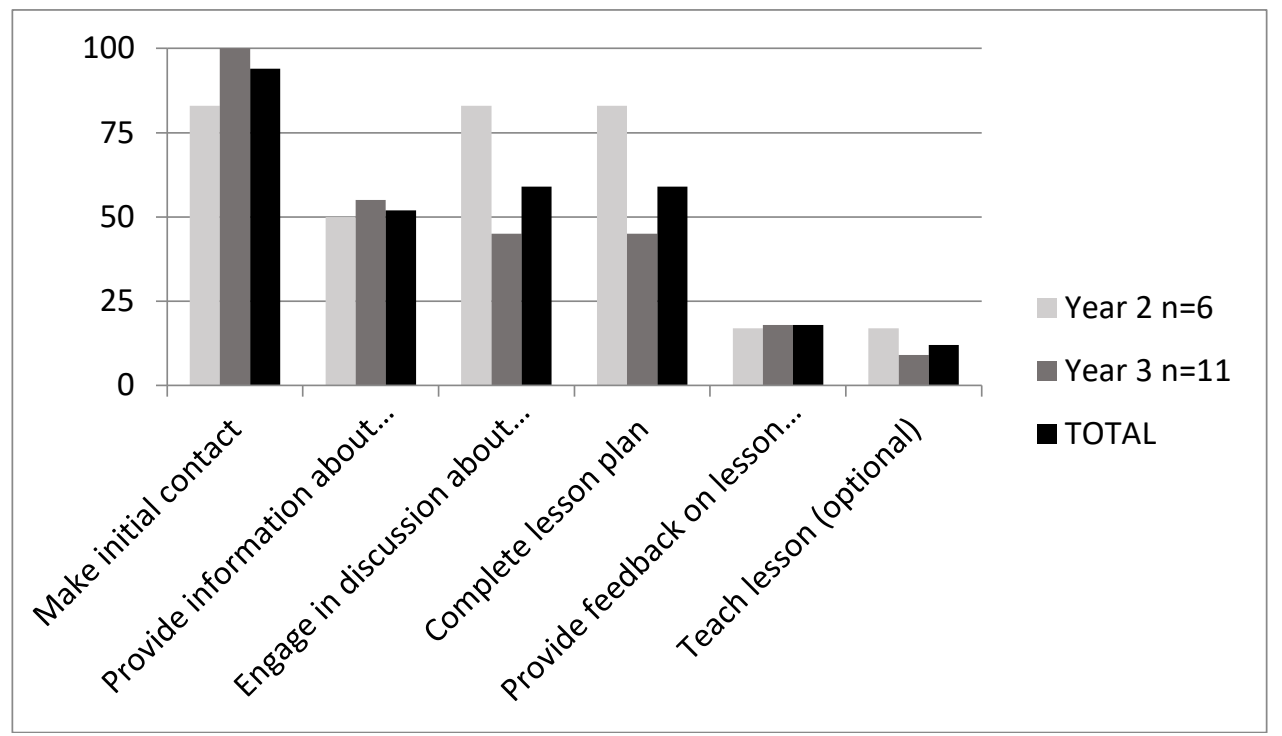

